\title{
Real-life use of onabotulinumtoxinA for symptom relief in patients with chronic migraine: REPOSE study methodology and baseline data
}

Brendan Davies ${ }^{1 *}$, Charly Gaul ${ }^{2}$, Paolo Martelletti ${ }^{3}$, Juan Carlos García-Moncó ${ }^{4}$ and Stephanie Brown ${ }^{5}$

\begin{abstract}
Background: Migraine is a debilitating neurological disorder that affects $14.1 \%$ of the US and $14.7 \%$ of the European populations. Chronic migraine (CM) is broadly defined as headache occurring on $\geq 15$ days per month for $\geq 3$ months, and has an estimated worldwide prevalence of $1.4 \%$ to $2.2 \%$. OnabotulinumtoxinA is currently approved for the treatment of CM in most European countries, and is the only preventative treatment approved for adults with CM, based on results from the PREEMPT clinical trial programme. The ongoing prospective, observational REal-life use of botulinum toxin for the symptomatic treatment of adults with chronic migraine, measuring healthcare resource utilisation, and Patient-reported OutcomeS observed in practice (REPOSE) Study aims to describe real-world healthcare resource utilisation and patient-reported outcomes over a 2-year period in Germany, Italy, Norway, Russia, Spain, Sweden, and the United Kingdom, among patients with CM prescribed onabotulinumtoxinA.

Methods: Herein, methodology and baseline characteristics of patients who participated for $\geq 6$ months in REPOSE are reported. No outcomes data are presented, although the methods for collecting these data are detailed. In REPOSE, onabotulinumtoxinA is administered at baseline and each follow-up visit (approximately every 3 months) during the 24month treatment period, according to the treating physician's best clinical judgment and standard of care, guided by the terms of the marketing authorisation described in the Summary of Product Characteristics. Outcome assessments include Migraine-Specific Quality of Life Questionnaire (MSQ), EuroQol Group Questionnaire (EQ-5D), headache-day frequency, treatment satisfaction, headache-related healthcare resource utilisation (ie, healthcare professional visits, hospital admissions, medication use), onabotulinumtoxinA utilisation (ie, dose, sites), and safety/tolerability.
\end{abstract}

Results: As of the interim assessment date for this analysis, the study has enrolled 644 patients from 78 sites throughout Europe, and baseline data are available for 336 patients from 61 sites who participated in the study for $\geq 6$ months. Baseline measures indicate substantial disease burden and healthcare resource utilisation.

Conclusions: Final results from the REPOSE Study will provide the largest real-world, long-term analysis of the clinical use of onabotulinumtoxinA for the treatment of $\mathrm{CM}$ and will add important information to existing real-world findings. Future analyses will assess the long-term safety and efficacy of onabotulinumtoxinA in this population.

\footnotetext{
* Correspondence: Brendan.davies@uhnm.nhs.uk

${ }^{1}$ Royal Stoke University Hospital, Newcastle Road, Stoke-on-Trent,

Staffordshire ST4 6QG, UK

Full list of author information is available at the end of the article
} 


\section{Background}

Migraine is a debilitating neurological disorder that affects $14.1 \%$ of the US $[1,2]$ and $14.7 \%$ of the European [3] populations. It can be categorised on the basis of headache-day frequency into episodic $(<15$ headache days/month) and chronic forms. Chronic migraine (CM) is defined by the International Classification of Headache Disorders (third edition, beta version [ICHD-3b]) as headache occurring on $\geq 15$ days per month for $>3$ months, with $\geq 8$ days per month meeting criteria for migraine with or without aura [4]. Chronic migraine has an estimated worldwide prevalence of $1.4 \%$ to $2.2 \%$ [5], and is associated with substantial disease burden. Compared with episodic migraine (EM), patients with CM suffer from greater disease impact [6], a higher level of disability [7, 8], higher scores for depression and anxiety [9], and reduced quality of life [7]. In addition, CM is associated with higher healthcare utilisation and reduced productivity, resulting in an overall greater economic burden compared with EM [10, 11, 7]. This economic burden has been reported to be reduced by onabotulinumtoxinA treatment in cases of CM refractory to $\geq 2$ oral prophylactics, with respect to migraine-related emergency department visits, urgent care visits, and hospitalisations [12].

Although several classes of medication are used as preventative treatments for CM (eg, beta blockers, antidepressants, muscle relaxants [eg, tizanidine], anticonvulsants) [13], most (with the exception of topiramate [an anticonvulsant] [14, 15] and amitriptyline [an antidepressant] [16, 17]) do not have empirical evidence of efficacy in CM. Furthermore, of these medicines, only topiramate and beta blockers are approved for migraine prevention (although neither is approved for CM prevention specifically). In addition, adherence to these medications is typically poor [18], largely due to adverse events [19] and possibly also due to lack of sustained efficacy. The lack of safety and efficacy of these agents suggests an unmet need for improved preventative treatment of CM $[19,20]$.

OnabotulinumtoxinA has received regulatory approval in most European countries as the only approved treatment for symptom relief in adults with CM [21]. Recommended treatment consists of intramuscular injections of $155 \mathrm{U}$ divided among 7 head/neck muscles administered in $\sim 12$-week intervals [22]. The Phase 3 REsearch Evaluating Migraine Prophylaxis Therapy (PREEMPT) clinical trials evaluated the safety and efficacy of onabotulinumtoxinA for the preventative treatment of CM. Compared with placebo, patients treated with 2 cycles of onabotulinumtoxin A (ie, 24 weeks) experienced a significant reduction in headache days (per 28-day period) and an improvement in quality of life [23, 24]. In a pooled analysis of those patients who continued treatment for an additional 3 cycles (ie, 52 weeks), a persistent improvement in the number of headache days and quality of life was observed with onabotulinumtoxinA [25]. Throughout the 52-week study period, onabotulinumtoxinA was generally well-tolerated, and the adverse event (AE) profile was consistent with previous reports.

The PREEMPT clinical trial programme provides support for the use of onabotulinumtoxinA for the preventative treatment of adults with $\mathrm{CM}$ over a 1-year period, and several subsequent studies have supported these findings in patients with and without medication overuse [26-33]. The ongoing prospective, observational REal-life use of botulinum toxin for the symptomatic treatment of adults with chronic migraine, measuring healthcare resource utilisation, and Patient-reported OutcomeS observed in practice (REPOSE) Study aims to describe real-world healthcare resource utilisation and patient-reported outcomes among patients with $\mathrm{CM}$ who were treated with onabotulinumtoxinA over a 2year period. This report will review the REPOSE Study methodology and baseline patient characteristics. No outcomes data are reported here, although the methods for collecting these data are detailed.

\section{Methods}

Study design

The REPOSE Study is an ongoing 24-month, prospective, non-interventional, observational study being conducted among 78 clinics throughout Germany, Italy, Norway, Russia, Spain, Sweden, and the United Kingdom. Patients prescribed onabotulinumtoxinA (BOTOX ${ }^{\oplus}$, Allergan plc, Dublin, Ireland) for symptom relief of $\mathrm{CM}$ are recruited over a 6- to 12-month period. The 24-month treatment period, including follow-up, is carried out per the treating physician's best clinical judgment and standard of care, guided by the terms of the marketing authorisation described in the Summary of Product Characteristics [34]. Treatment, therefore, reflects the individual physician's usual clinical routine and country-specific standards of care. The total study duration is 30 to 36 months and consists of enrollment, a baseline visit (visit 1) and follow-up visits approximately every 3 months. A window of at least 15 days spanned the 3-month follow-up time point, such that 3 slightly different groups could be defined as follows: less than 3 months, $<75$ days since the last injection; every 3 months, $\geq 75$ and $<105$ days since the last injection; more than 3 months, $\geq 105$ days since the last injection. OnabotulinumtoxinA injections are administered at baseline and each follow-up visit. All participating clinics obtain appropriate ethics committee approval and the study is being conducted in accordance with International Conference on Harmonisation Good Clinical Practice. All patients provide written informed consent. 


\section{Study treatment}

Treating physicians are trained on onabotulinumtoxinA injection patterns as described in the Summary of Product Characteristics [34] and the PREEMPT study paradigm [35]; although there was no mandate for physician's to comply with these injection paradigms. Onabotulinumtoxin A is administered in $0.1 \mathrm{~mL}$ injections $(5 \mathrm{U})$ using a 30gauge, 0.5 -in. needle. The minimum recommended dose of onabotulinumtoxinA is $155 \mathrm{U}$ injected bilaterally into 31 sites among 7 head and neck muscles. At the physician's discretion, the protocol allows for an additional 8 injections according to the 'follow-the-pain' strategy for a total dose of $195 \mathrm{U}$ [35]. Injection sites and recommended doses are outlined in Table 1.

The cost of onabotulinumtoxinA and treatments reflected real-world costs, and varied depending on country and insurance status of the patient.

\section{Patient selection}

This report includes patients who participated for $\geq 6$ months based on an interim analysis date of February 12 , 2015. Male and female patients aged $\geq 18$ years who are prescribed onabotulinumtoxinA for CM symptom relief are enrolled. Patients are excluded if they had received any botulinum toxin serotype within the previous 26 weeks, if they are currently participating in the Botox Chronic Migraine Post-Authorisation Safety Study (CM PASS), or if they are contraindicated for treatment with onabotulinumtoxinA per the prescribing information. Given the observational nature of this study, no other formal exclusion criteria have been defined. Patients are free to leave the study at any time, independent of their response to treatment. Any pregnancies that occur during the study are reported to Allergan via the electronic case report form (eCRF) within $24 \mathrm{~h}$ of confirmation. In addition, the patient's primary care physician is notified that the patient has been treated with onabotulinumtoxinA. The patient is then withdrawn from the study with a safety follow up of at least 12 weeks and is followed to

Table 1 OnabotulinumtoxinA Injection Sites and Doses [35]

\begin{tabular}{|c|c|c|}
\hline $\begin{array}{l}\text { Muscle Injection } \\
\text { Site }\end{array}$ & $\begin{array}{l}\text { Minimum } \\
\text { Recommended Dose }\end{array}$ & $\begin{array}{l}\text { Additional Injections per the } \\
\text { 'Follow-the-Pain' Strategy }\end{array}$ \\
\hline Frontalis & 20 U, 4 sites & NA \\
\hline Corrugator & 10 U, 2 sites & NA \\
\hline Procerus & 5 U, 1 site & NA \\
\hline Occipitalis & 30 U, 6 sites & 10 U, 2 sites \\
\hline Temporalis & $40 \mathrm{U}, 8$ sites & $10 \mathrm{U}, 2$ sites \\
\hline Trapezius & 30 U, 6 sites & 20 U, 4 sites \\
\hline $\begin{array}{l}\text { Cervical paraspinal } \\
\text { muscle group }\end{array}$ & 20 U, 4 sites & NA \\
\hline
\end{tabular}

term by the treating physician. A final pregnancy outcome report is then provided to Allergan.

\section{Assessments}

At the baseline visit, patients are screened for inclusion criteria, provide informed consent, and receive their first treatment with onabotulinumtoxinA. Baseline assessments include demographics (ie, age, gender, height, weight, body mass index [BMI], education and employment status), medical history, and migraine history (ie, diagnosis, age of onset, time since diagnosis of migraine, and time since diagnosis of CM). All efficacy, healthcare resource utilisation, onabotulinumtoxinA utilisation, safety, and tolerability data are assessed at baseline and each follow-up visit as described below.

\section{Efficacy}

Patient-reported efficacy measures include the MigraineSpecific Quality of Life Questionnaire (MSQ) version 2.1, the EuroQol Group EQ-5D Questionnaire, patientreported estimation of headache day frequency, and patient-reported treatment satisfaction.

The MSQ version 2.1 is a 14-item quality of life questionnaire that measures the impact of migraine on daily activities. The scale consists of 3 domains: 1 ) role restriction (questions 1-7) describes the degree which daily activities are limited; 2) role prevention (questions 8-11) describes the degree which daily activities are interrupted; and 3) emotional function (questions 12-14) describes the feelings of helplessness and frustration resulting from migraine. Each item is scored on a 6 -point scale $(1=$ none of the time; 2 = a little bit of the time; 3 = some of the time; 4 = a good bit of the time; 5 = most of the time; $6=$ all of the time); dimension and total scores are calculated as the sum of the raw item scores rescaled from 0 to 100 , where a higher score indicates a better quality of life [7, 36, 37]. The MSQ is reported as change from baseline in total and dimension scores.

The EuroQol Group EQ-5D questionnaire assigns an overall health state classification, reported as an index score and a patient-reported visual analog scale (VAS) health state score. The index score is calculated on the basis of 5 dimensions: 1) mobility; 2) self-care; 3) usual activities; 4) pain/discomfort; and 5) anxiety/depression, with each dimension rated on a 3 -point scale $(1=$ no problems; 2 = some problems; 3 = extreme problems). Starting with a score of 1.0, weighted scores are deducted on the basis of each dimension's rating to yield an outcome score ranging from -0.59 to 1.00 . A score of 1.00 indicates 'full health', a score of 0 indicates 'death', and a negative score indicates a health state that is perceived to be worse than death [38]. The VAS score is a patientreported measure of the current health state ranging from 0 (worst health imaginable) to 100 (best imaginable health 
state). The EQ-5D is reported as change from baseline in the index and health state scores, as well as a frequency distribution of perceived problems for each dimension.

The frequency of headache days is estimated by each patient as the number of days within the past month with $\geq 4 \mathrm{~h}$ of continuous headache.

Satisfaction with onabotulinumtoxinA treatment is assessed by both the patient and the prescribing physician as 'insufficient,' 'moderate,' 'good,' or 'very good' and is reported as a frequency distribution of satisfaction level as well as the proportion of patients and physicians who rated satisfaction as 'good' or 'very good.'

\section{Healthcare utilisation}

The frequency of headache-related healthcare professional (HCP) visits (by type: primary care consultation, outpatient consultation, accident and emergency visit, alternative practitioner, and other) and hospital admissions for headache are recorded for each period between visits. The total number of HCP visits and hospital admissions are normalised to 90 days using the following formula: $(90 \div$ number of days between periods $) \times$ number of visits to HCPs or admissions to hospitals between periods. The frequency and proportion of patients who had visits or admissions between each visit is compared with those of the 3 months before baseline. At baseline, a complete medication history is documented, including headache medication used at any time before baseline, headache medication or therapy prescribed in the 26 weeks before baseline, and headache medication prescribed in the 26 weeks before baseline and in use at baseline. In addition, medication overuse, as assessed by the treating physician (not required to be based on ICHD criteria), is also recorded. All headache medications and therapies are categorised by indication (ie, acute, preventative, complementary) and drug class, and any changes in medication use are documented at each follow-up visit.

\section{OnabotulinumtoxinA utilisation}

Details of injection dose and site are documented during each treatment visit. For each visit, treating physicians document the total dose per treatment session and dose per muscle injected, as well as the number of muscle areas injected and the total number and locations of injection sites. These data are recorded for all patients receiving the PREEMPT recommended basic injections as well as for those patients who are treated with the 'follow-the-pain' strategy.

\section{Safety and tolerability}

The safety of onabotulinumtoxinA treatment is assessed via adverse drug reaction (ADR) reporting, including frequency, severity (ie, mild, moderate, severe), and relation (ie, definite, probable, possible, not assessable) to onabotulinumtoxinA. All treating physicians are required to document ADRs in the eCRF. Physician- and patientreported onabotulinumtoxinA tolerability is rated as 'insufficient,' 'moderate,' 'good,' or 'very good,' and reported as the proportion of patients and physicians who rate the tolerability to be 'good' or 'very good.'

\section{Statistical analysis}

All baseline, demographic, efficacy, and safety analyses are performed in the safety analysis set (ie, all patients who receive $\geq 1$ dose of onabotulinumtoxinA). Descriptive statistics are used to describe continuous variables; frequency and proportion distributions are used to report categorical data. Changes from baseline at each follow-up visit are analysed at the two-sided 5\% level using a nonparametric Wilcoxon signed rank test. All data are analysed as reported in the database using $\mathrm{SAS}^{\circ}$ version 9.3 (SAS Institute, Inc., Cary, NC); any missing data are reported as such. If any dimension score on the EQ-5D or question on the MSQ is missing, the corresponding dimension and total scores are reported as missing.

\section{Results \\ Disposition and demographics}

Since the first patient was enrolled in July, 2012, the study has enrolled 644 patients from 78 sites throughout Europe. As of the cutoff date for this interim analysis (February 12, 2015), baseline data are available from 61 sites for 336 patients who participated in the study for $\geq 6$ months. All patients received $\geq 1$ dose of onabotulinumtoxinA and are included in the safety analysis set. The number of patients who completed and provided data for baseline and up to 4 follow-up visits is displayed in Fig. 1. Four patients discontinued the study (no future treatments scheduled, $n=2$; discontinued onabotulinumtoxinA, $n=2$ ); no specific reasons for discontinuing onabotulinumtoxinA were specified in the eCRF.

Baseline patient demographic characteristics are presented in Table 2. The mean (SD) age was 44.9 (11.4) years and BMI was $24.5(4.5) \mathrm{kg} / \mathrm{m}^{2}$. Most patients $(85.4 \%)$ were women, had a secondary school certificate (55.1\%), and were employed either full- or part-time (66.1\%).

\section{Medical and headache history}

Patient headache-related disease history at baseline is presented in Table 3. The mean (SD) patient-reported age of headache onset was 18.5 (9.3) years. The mean (SD) time since migraine diagnosis was 19.5 (12.1) years and CM diagnosis was 5.1 (7.6) years. The mean (SD) patient-estimated headache-day frequency (ie, any day with $\geq 4 \mathrm{~h}$ of continuous headache) was 


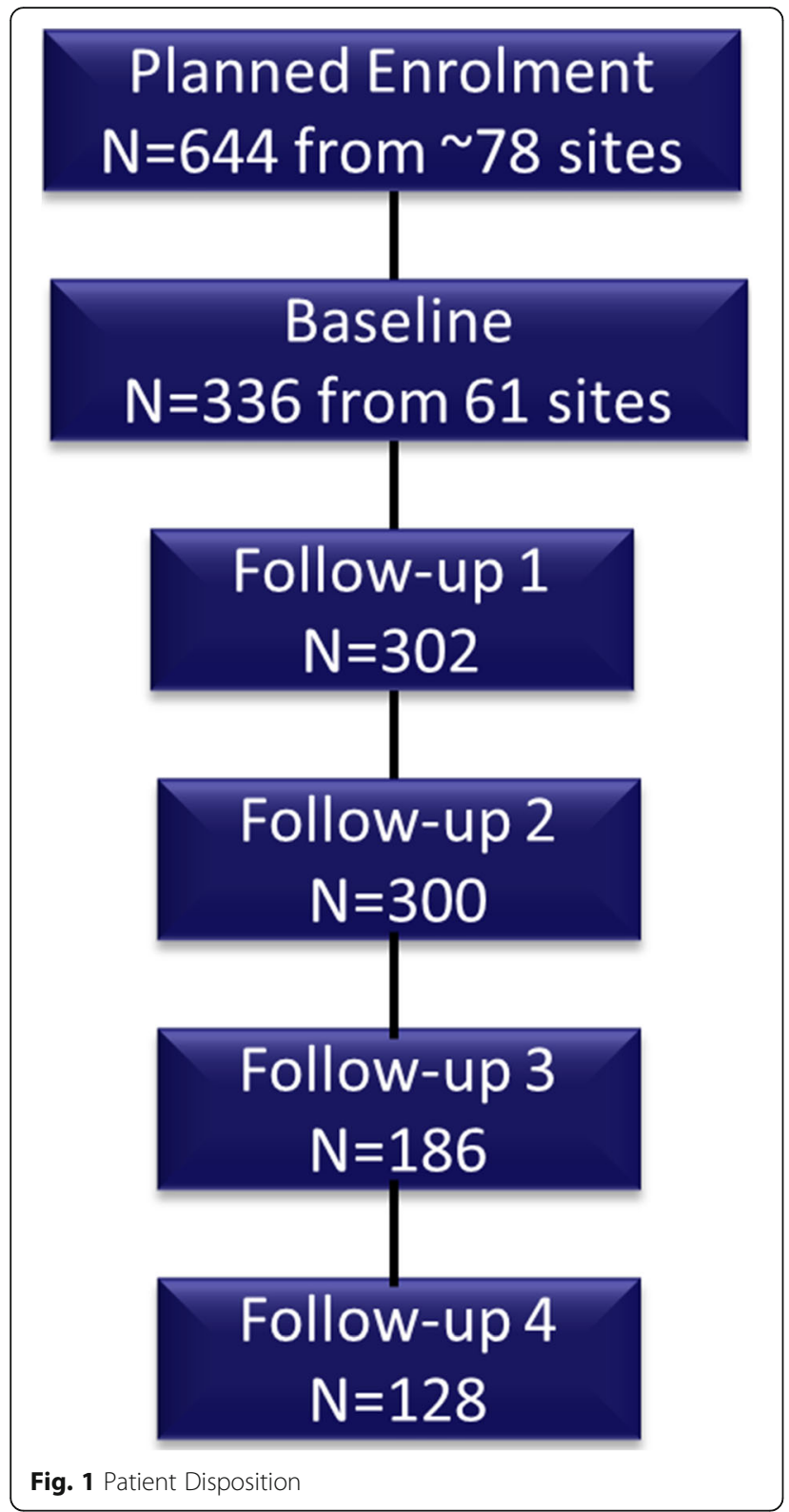

20.6 (5.3) days per month. Based on the treating physician's clinical judgment, it was determined that approximately one-third of the patients $(34.2 \%)$ had $\mathrm{CM}$ complicated by medication overuse (including medication overuse, rebound, or analgesic overuse headaches). Baseline quality of life measures indicate substantial disease burden, as measured by mean (SD) MSQ (56.2 [12.4]), EQ-5D index (0.47 [0.38]), and EQ-5D VAS scores (47.7 [25.1]).

\section{Healthcare resource and medication utilisation}

In the 3 months before baseline, a small proportion ( 4\%) of patients had been admitted to the hospital for headache. Conversely, HCP visits were more frequent;
Table 2 Patient Demographics

\begin{tabular}{|c|c|}
\hline Characteristic & $\begin{array}{l}\text { 6-Month Completers } \\
(n=336)^{\text {a }}\end{array}$ \\
\hline \multicolumn{2}{|l|}{ Age (years) } \\
\hline Mean (SD) & $44.9(11.4)$ \\
\hline Median (min, max) & $46.0(18,76)$ \\
\hline \multicolumn{2}{|l|}{ Age group (years), n (\%) } \\
\hline$\geq 18$ and $<30$ & $33(9.8)$ \\
\hline$\geq 30$ and $<40$ & $80(23.8)$ \\
\hline$\geq 40$ and $<50$ & $107(31.8)$ \\
\hline$\geq 50$ & $115(34.2)$ \\
\hline \multicolumn{2}{|l|}{ Gender, n (\%) } \\
\hline Male & 49 (14.6) \\
\hline Female & $287(85.4)$ \\
\hline \multicolumn{2}{|l|}{ Weight (kg) } \\
\hline Mean (SD) & $68.6(14.3)$ \\
\hline Median (min, max) & $65(46,150)$ \\
\hline \multicolumn{2}{|l|}{ Height (cm) } \\
\hline Mean (SD) & $167.4(8.3)$ \\
\hline Median (min, max) & $167(150,203)$ \\
\hline \multicolumn{2}{|l|}{ Body mass index $\left(\mathrm{kg} / \mathrm{m}^{2}\right)$} \\
\hline Mean (SD) & $24.5(4.5)$ \\
\hline Median (min, max) & $24(16,43)$ \\
\hline \multicolumn{2}{|l|}{ Education, n (\%) ${ }^{\mathrm{b}}$} \\
\hline No school-leaving qualifications & $6(1.8)$ \\
\hline Still attending school & 0 \\
\hline Secondary school certificate ('Hauptschule') & $69(20.5)$ \\
\hline Secondary school certificate ('Realschule') & $116(34.5)$ \\
\hline Higher education entrance qualification & $71(21.1)$ \\
\hline University degree & $59(17.6)$ \\
\hline \multicolumn{2}{|l|}{ Employment Status, n (\%) } \\
\hline Full time & $179(53.3)$ \\
\hline Part time & $43(12.8)$ \\
\hline Retiree & $20(6.0)$ \\
\hline Unemployed & $20(6.0)$ \\
\hline Pupil & $1(0.3)$ \\
\hline Trainee & $3(0.9)$ \\
\hline Student & $6(1.8)$ \\
\hline Self-employed & $10(3.0)$ \\
\hline Housewife/husband & $26(7.7)$ \\
\hline Side job & $4(1.2)$ \\
\hline Pensioner & $15(4.5)$ \\
\hline
\end{tabular}

${ }^{a}$ Only gender data was available for 1 patient

${ }^{\mathrm{b}}$ Education data were unavailable for 15 patients

${ }^{C}$ Employment data were unavailable for 9 patients 
Table 3 Disease History of Patients with CM

\begin{tabular}{|c|c|c|}
\hline & & $\begin{array}{l}\text { 6-Month Completers } \\
(n=336)\end{array}$ \\
\hline \multirow[t]{3}{*}{ Time since first diagnosis of $\mathrm{CM}$, years } & $\mathrm{N}$ & 336 \\
\hline & Mean (SD) & $5.1(7.6)$ \\
\hline & Median (min, max) & $1.8(-0.8,40.6)^{\mathrm{a}}$ \\
\hline \multirow[t]{3}{*}{ Age of onset, years ${ }^{b}$} & N & 331 \\
\hline & Mean (SD) & $18.5(9.3)$ \\
\hline & Median (min, max) & $16(3,57)$ \\
\hline \multirow[t]{3}{*}{ Time since first diagnosis of migraine, years } & $\mathrm{N}$ & 330 \\
\hline & Mean (SD) & $19.5(12.1)$ \\
\hline & Median (min, max) & $19.8(-0.2,71)^{\mathrm{a}}$ \\
\hline \multirow[t]{13}{*}{ Non-CM headache diagnoses, $\mathrm{n}(\%)^{\mathrm{d}}$} & Migraine & $245(72.9)$ \\
\hline & Medication overuse ${ }^{c}$ & $115(34.2)$ \\
\hline & Tension headache & $83(24.7)$ \\
\hline & Chronic tension-type headache & $41(12.2)$ \\
\hline & Chronic daily headache & $39(11.6)$ \\
\hline & Menstrual headache or menstrual migraine & $28(8.3)$ \\
\hline & Stress headache & $28(8.3)$ \\
\hline & Intractable/refractory migraine or headache & $21(6.3)$ \\
\hline & Cluster headache & $8(2.4)$ \\
\hline & Sinus headache & $4(1.2)$ \\
\hline & Hemicrania continua & $1(0.3)$ \\
\hline & New daily persistent headache & 0 \\
\hline & Other & $5(1.5)$ \\
\hline
\end{tabular}

$\mathrm{CM}=$ chronic migraine

${ }^{a}$ The negative minimum value results from incorrect dates in the electronic case report form. The date of the baseline visit was prior to the date of the first diagnosis in 1 patient

${ }^{\mathrm{b}}$ Based on the patient's recollection

'Includes any diagnosis of medication overuse, rebound, or analgesic overuse headache, based on the treating physician's clinical judgment

${ }^{\mathrm{d}}$ Multiple answers were possible

$42.9 \%$ of patients had a mean (SD) of 3.5 (4.0) $\mathrm{HCP}$ visits in the 3 months before baseline. The most frequently used (ie, $\geq 50 \%$ of patients) headache medications at any time before the study were beta blockers, antidepressants, and antiepileptics ( $70 \%$ each). Only $7.1 \%$ of patients had previously received botulinum toxin for treatment of headache (Table 4). During the 26 weeks before baseline, a large proportion (90.8\%) of patients had been prescribed some type of headache medication. At baseline, $80.7 \%$ of patients were using prescribed acute headache medications, resulting in approximately one-fifth of patients (19.3\%) not using prescribed acute headache medications. Prescribed preventative headache medications were in use by $50.0 \%$ of the patients. The most frequently used (prescription and nonprescription) acute headache medications were triptans and ibuprofen, and the most frequent preventative medication was topiramate (Table 4 ). According to the treating physician, $40 \%$ of patients were overusing their headache medications at baseline.

\section{Discussion}

To date, the PREEMPT clinical trial programme is the largest study of onabotulinumtoxin A in $\mathrm{CM}$ and provides evidence for safety and efficacy over a 52-week treatment period [23-25]. The purpose of the REPOSE study is to provide real-world data, observed in a clinical setting, regarding the use of onabotulinumtoxinA for the treatment of CM over a 2-year period, as measured by patient- and physician-reported efficacy outcomes, healthcare resource utilisation, and adverse event profile. These data are intended to complement and strengthen previously published rigorously controlled studies and real-world analyses by supplying previously unreported information about the real-world long-term impact of onabotulinumtoxin A on CM patient healthcare utilisation patterns and 
Table 4 Medication History

\begin{tabular}{ll}
\hline & $\begin{array}{l}6-\text { Month Completers } \\
(n=336)\end{array}$ \\
\hline Previous headache medication, $\mathrm{n}(\%)^{\mathrm{a}}$ & $238(70.8)$ \\
Beta blockers & $235(69.9)$ \\
Antidepressants & $227(67.6)$ \\
Antiepileptics & $102(30.4)$ \\
Calcium channel blockers & $24(7.1)$ \\
Botulinum toxin & \\
Medication/therapy prescribed in the 26 & \\
weeks before baseline, $\mathrm{n}(\%)^{\mathrm{a}}$ & $305(90.8)$ \\
Any headache medication/therapy & $283(84.2)$ \\
Acute treatment for headache & $211(62.8)$ \\
Headache prevention & $73(21.7)$ \\
Complementary therapies & \\
Medication/therapy prescribed in the 26 weeks & \\
before baseline and used by the patient at & \\
baseline, $\mathrm{n}(\%){ }^{\mathrm{a}, \mathrm{b}}$ & \\
Headache prevention & \\
Topiramate & $168(50.0)$ \\
Acute treatment for headache & $57(17.0)$ \\
Sumatriptan & $271(80.7)$ \\
Ibuprofen & $95(28.3)$ \\
Rizatriptan & $75(22.3)$ \\
Zolmitriptan & $43(12.8)$ \\
\hline
\end{tabular}

${ }^{a}$ Multiple answers were possible

${ }^{\mathrm{b}}$ Medications/therapies which were used at baseline by at least $10 \%$ of the patients

disease burden including poor quality of life, which is an important distinguishing feature of CM $[39,40]$.

As of the database cutoff date, baseline data were available for approximately half (336/644) of the enrolled patient population. Consistent with previous research $[10,41,7]$, the majority of patients $(\sim 80 \%)$ in the current study are female, with a mean age of $\sim 45$ years, substantial disease burden (as measured by the MSQ), and most have previously used beta-blockers, antidepressants, or antiepileptics for treatment of CM. Nevertheless, some differences were observed between this European population and the US population of patients with $\mathrm{CM}$. One notable difference is the mean BMI; patients in the current study have a lower BMI $\left(24.5 \mathrm{~kg} / \mathrm{m}^{2}\right)$ than that observed among patients with $\mathrm{CM}$ in a large US epidemiologic study (American Migraine Prevalence and Prevention Study [AMPP]; $30.4 \mathrm{~kg} / \mathrm{m}^{2}$ ) [6]. This dissimilarity may reflect international differences in BMI (general population mean BMI: 23.8 to $25.3 \mathrm{~kg} / \mathrm{m}^{2}$ for women and 25.5 to $26.3 \mathrm{~kg} / \mathrm{m}^{2}$ for men in 9 European countries [42];
$28.7 \mathrm{~kg} / \mathrm{m}^{2}$ for women and $28.6 \mathrm{~kg} / \mathrm{m}^{2}$ for men in the United States [43]. Additionally, patients in the current study have higher rates of full- or part-time employment (66.1\%) compared with those from 2 US epidemiologic studies (Chronic Migraine Epidemiology and Outcomes Study, 56.4\%; AMPP, 47\%) [44, 45], although, again, this may partly reflect population differences due to study design.

In contrast with expectations, an unexpected low rate of intractable/refractory migraine or headache was observed, which may be attributed to inconsistencies in diagnosis among treating physicians or a possible low participation of headache specialists in the study. Coinciding with the timeframe of this study, there was debate on the definition of refractory CM (due to the introduction of onabotulinumtoxin A as a preventive treatment), resulting in a proposal from the European Headache Federation Expert Group to modify the definition to also include patients who had contraindications to or no effect from onabotulinumtoxinA treatment. [46] This "tightening" of the definition of refractory $\mathrm{CM}$ could have led to the low rate of intractable/refractory migraine observed. In addition, the time since first diagnosis of migraine and $\mathrm{CM}$ were $\sim 20$ and $\sim 5$ years, respectively, which may indicate that migraine chronification occurs over a protracted period. Although adherence is not being directly measured in the current study, approximately one-fifth of patients are not using their acute headache medications as prescribed. Furthermore only $50 \%$ of patients are using their prescribed preventative medications at baseline. This is slightly higher than the $\sim 30 \%$ adherence rate observed in a study of the adherence of preventative oral medications for CM [18]; however, further investigation is required to understand why patients with $\mathrm{CM}$ are not taking their medications as prescribed, but it is possible that a lack of sustained effectiveness or the presence of troublesome side effects contribute to poor compliance.

This report of baseline data from the REPOSE study has some limitations. The observational nature of the study reflecting real-world use of onabotulinumtoxinA precludes any utilisation of formal protocol requirements or exclusion criteria. One consequence of this study design is that treatments were not mandated, but were provided at the participating physicians' discretion according to their clinical judgment and local standards of medical care. Another consequence is the observed variety of diagnoses and the inability to disentangle comorbidities that might influence treatment outcomes. In addition, since headache diaries were not used, the patient-reported outcomes relied on patient recollection and reporting compliance, which may result in incomplete and/or missing data. 


\section{Conclusion}

The REPOSE Study will provide the largest real-world, long-term analysis of the clinical use of onabotulinumtoxinA for the treatment of CM and will add important information to existing real-world findings. Future analyses will assess the long-term safety and efficacy of onabotulinumtoxinA in this population.

\begin{abstract}
Abbreviations
ADR: Adverse drug reaction; AE: Adverse event; AMPP: American Migraine Prevalence and Prevention Study; BMI: Body mass index; CM: Chronic migraine; CM-PASS: Botox Chronic Migraine Post-Authorisation Safety Study; eCRF: Electronic case report form; EM: Episodic migraine; EQ-5D: EuroQol Group Questionnaire; HCP: Healthcare professional; ICHD-3b: International Classification of Headache Disorders (third edition, beta version); MSQ: Migraine-Specific Quality of Life Questionnaire; NA: Not applicable; PREEMPT: The Phase 3 REsearch Evaluating Migraine Prophylaxis Therapy; REPOSE: REal-life use of botulinum toxin for the symptomatic treatment of adults with chronic migraine, measuring healthcare resource utilisation, and Patient-reported OutcomeS observed in practice; VAS: Visual analog scale
\end{abstract}

\section{Acknowledgments}

This study was sponsored by Allergan plc (Dublin, Ireland). Writing and editorial assistance was provided to the authors by Amanda Kelly, MPhil, MSHN, of Complete Healthcare Communications, LLC (West Chester, PA), and funded by Allergan plc (Dublin, Ireland). All authors met the International Conference of Medical Journal Editors authorship criteria. Neither honoraria nor payments were made for authorship.

\section{Authors' contributions}

BD, PM, and JCG-M participated in study conception and design. BD, CG, PM, and JCG-M participated in data acquisition. BD, CG, PM, JCG-M, and SB participated in data analysis and interpretation. All authors read and approved the final manuscript.

\section{Competing interests}

Financial arrangements of the authors with companies whose products may be related to the present report are listed below, as declared by the authors. Brendan Davies is the Clinical and Research lead of the Midlands headache clinic, University Hospital of North Midlands. He has received consultancy honoraria from Allergan, AMGEN and UK research study funding via the UK NIHR from AMGEN and Eli Lilly. Dr. Davies has no ownership interests or pharmaceutical company stocks. Charly Gaul is the director of the migraine and headache clinic Königstein. He received honoraria from Allergan, Desitin, Lilly, electroCore, Grünenthal, Bayer, Boehringer Ingelheim, Autonomic Technologies, Ratiopharm, Novartis Pharma, Desitin Arzneimittel, Cerbotec, Reckitt Benckiser and Hormosan. Dr. Gaul has no ownership interests and does not own any pharmaceutical company stocks. Paolo Martelletti declares that he has received research funds or advisory board honoraria from Allergan, Teva, and Bayer. Juan Carlos García-Moncó declares no potential conflicts of interest. Stephanie Brown is an employee of Allergan plc (Marlow, Buckinghamshire, UK).

\section{Publisher's Note}

Springer Nature remains neutral with regard to jurisdictional claims in published maps and institutional affiliations.

\section{Author details}

${ }^{1}$ Royal Stoke University Hospital, Newcastle Road, Stoke-on-Trent, Staffordshire ST4 6QG, UK. ${ }^{2}$ Migraine and Headache Clinic Königstein, Königstein im Taunus, Germany. ${ }^{3}$ Regional Referral Headache Centre, Sapienza University, Rome, Italy. ${ }^{4}$ Hospital de Galdacano, Vizcaya, Bilbao, Spain. ${ }^{5}$ Allergan plc, Marlow, Buckinghamshire, UK.
Received: 21 December 2016 Accepted: 18 August 2017

Published online: 06 September 2017

\section{References}

1. Centers for Disease Control and Prevention (2014) Summary Health Statistics for U.S. Adults: National Health Interview Survey, 2012

2. Burch RC, Loder S, Loder E, Smitherman TA (2015) The prevalence and burden of migraine and severe headache in the United States: updated statistics from government health surveillance studies. Headache 55:21-34. doi:10.1111/head.12482

3. Stovner LJ, Andree C (2010) Prevalence of headache in Europe: a review for the Eurolight project. J headache pain 11:289-299. doi:10.1007/s10194-010-0217-0

4. Headache Classification Committee of the International Headache Society (2013) The international classification of headache disorders, 3rd edition (beta version). Cephalalgia 33:629-808. doi:10.1177/0333102413485658

5. Natoli JL, Manack A, Dean B, Butler Q, Turkel CC, Stovner L, Lipton RB (2010) Global prevalence of chronic migraine: a systematic review. Cephalalgia 30: 599-609. doi:10.1111/j.1468-2982.2009.01941.x

6. Buse DC, Manack AN, Serrano D, Reed ML, Varon S, Turkel CC, Lipton RB (2012) Headache impact of chronic and episodic migraine: results from the American migraine prevalence and prevention study. Headache 52:3-17. doi:10.1111/j.1526-4610.2011.02046.x

7. Blumenfeld AM, Varon SF, Wilcox TK, Buse DC, Kawata AK, Manack A Goadsby PJ, Lipton RB (2011) Disability, HRQoL and resource use among chronic and episodic migraineurs: results from the International Burden of Migraine Study (IBMS). Cephalalgia 31:301-315. doi:10.1177/ 0333102410381145

8. Lanteri-Minet M, Duru G, Mudge M, Cottrell S (2011) Quality of life impairment, disability and economic burden associated with chronic daily headache, focusing on chronic migraine with or without medication overuse: a systematic review. Cephalalgia 31:837-850. doi:10.1177/ 0333102411398400

9. Ruscheweyh R, Muller M, Blum B, Straube A (2014) Correlation of headache frequency and psychosocial impairment in migraine: a cross-sectional study. Headache 54:861-871. doi:10.1111/head.12195

10. Bloudek LM, Stokes M, Buse DC, Wilcox TK, Lipton RB, Goadsby PJ, Varon SF, Blumenfeld AM, Katsarava Z, Pascual J, Lanteri-Minet M, Cortelli P, Martelletti $P$ (2012) Cost of healthcare for patients with migraine in five European countries: results from the International Burden of Migraine Study (IBMS). J headache pain 13:361-378. doi:10.1007/s10194-012-0460-7

11. Munakata J, Hazard E, Serrano D, Klingman D, Rupnow MF, Tierce J, Reed M, Lipton RB (2009) Economic burden of transformed migraine: results from the American Migraine Prevalence and Prevention (AMPP) study. Headache 49:498-508. doi:10.1111/j.1526-4610.2009.01369.x

12. Rothrock JF, Bloudek LM, Houle TT, Andress-Rothrock D, Varon SF (2014) Real-world economic impact of onabotulinumtoxinA in patients with chronic migraine. Headache 54:1565-1573. doi:10.1111/head.12456

13. Starling AJ, Dodick DW (2015) Best practices for patients with chronic migraine: burden, diagnosis, and management in primary care. Mayo Clin Proc 90:408-414

14. Silberstein SD, Lipton RB, Dodick DW, Freitag FG, Ramadan N, Mathew N, Brandes JL, Bigal M, Saper J, Ascher S, Jordan DM, Greenberg SJ, Hulihan J (2007) Efficacy and safety of topiramate for the treatment of chronic migraine: a randomized, double-blind, placebo-controlled trial. Headache 47:170-180

15. Diener HC, Bussone G, Van Oene JC, Lahaye M, Schwalen S, Goadsby PJ (2007) Topiramate reduces headache days in chronic migraine: a randomized, double-blind, placebo-controlled study. Cephalalgia 27:814-823

16. Santiago MD, Carvalho Dde S, Gabbai AA, Pinto MM, Moutran AR, Villa TR (2014) Amitriptyline and aerobic exercise or amitriptyline alone in the treatment of chronic migraine: a randomized comparative study. Arq Neuropsiquiatr 72:851-855

17. Couch JR, Amitriptyline Versus Placebo Study G (2011) Amitriptyline in the prophylactic treatment of migraine and chronic daily headache. Headache 51:33-51

18. Hepp Z, Dodick DW, Varon SF, Gillard P, Hansen RN, Devine EB (2015) Adherence to oral migraine-preventive medications among patients with chronic migraine. Cephalalgia 35:478-488

19. Hepp Z, Bloudek LM, Varon SF (2014) Systematic review of migraine prophylaxis adherence and persistence. J Manag Care Pharm 20:22-33 
20. Serrano D, Buse DC, Manack Adams A, Reed ML, Lipton RB (2015) Acute treatment optimization in episodic and chronic migraine: results of the American Migraine Prevalence and Prevention (AMPP) study. Headache 55:502-518

21. Allergan, Inc. (2015) Summary of product characteristics (Botox ${ }^{\oplus}$ [onabotulinumtoxinA for injection])

22. BOTOX ${ }^{\circledR}$ COSMETIC (onabotulinumtoxinA) for injection, for intramuscular use. Full Prescribing Information, Allergan, Inc., Irvine, CA, 2013

23. Aurora SK, Dodick DW, Turkel CC, DeGryse RE, Silberstein SD, Lipton RB, Diener HC, Brin MF (2010) OnabotulinumtoxinA for treatment of chronic migraine: results from the double-blind, randomized, placebo-controlled phase of the PREEMPT 1 trial. Cephalalgia 30:793-803. doi:10.1177/ 0333102410364676

24. Diener HC, Dodick DW, Aurora SK, Turkel CC, DeGryse RE, Lipton RB, Silberstein SD, Brin MF (2010) OnabotulinumtoxinA for treatment of chronic migraine: results from the double-blind, randomized, placebo-controlled phase of the PREEMPT 2 trial. Cephalalgia 30:804-814. doi:10.1177/ 0333102410364677

25. Aurora SK, Winner P, Freeman MC, Spierings EL, Heiring JO, DeGryse RE, VanDenburgh AM, Nolan ME, Turkel CC (2011) OnabotulinumtoxinA for treatment of chronic migraine: pooled analyses of the 56-week PREEMPT clinical program. Headache 51:1358-1373. doi:10.1111/j.1526-4610.2011.01990.x

26. Ahmed F, Zafar HW, Buture A, Khalil M (2015) Does analgesic overuse matter? Response to OnabotulinumtoxinA in patients with chronic migraine with or without medication overuse. SpringerPlus 4:589. doi:10.1186/s40064015-1386-8

27. Negro A, Curto M, Lionetto L, Crialesi D, Martelletti P (2015) OnabotulinumtoxinA $155 \mathrm{U}$ in medication overuse headache: a two years prospective study. Spring 4:826. doi:10.1186/s40064-015-1636-9

28. Negro A, Curto M, Lionetto L, Martelletti P (2015) A two years open-labe prospective study of OnabotulinumtoxinA $195 \mathrm{U}$ in medication overuse headache: a real-world experience. J Headache Pain 17:1. doi:10.1186/ s10194-016-0591-3

29. Pedraza Ml, de la Cruz C, Ruiz M, Lopez-Mesonero L, Martinez E, de Lera M, Guerrero AL (2015) OnabotulinumtoxinA treatment for chronic migraine: experience in 52 patients treated with the PREEMPT paradigm. Spring 4:176. doi:10.1186/s40064-015-0957-z

30. Khalil M, Zafar HW, Quarshie V, Ahmed F (2014) Prospective analysis of the use of OnabotulinumtoxinA (BOTOX) in the treatment of chronic migraine; real-life data in 254 patients from Hull, U.K. J Headache Pain 15:54

31. Guerzoni S, Pellesi L, Baraldi C, Pini LA (2015) Increased efficacy of regularly repeated cycles with OnabotulinumtoxinA in $\mathrm{MOH}$ patients beyond the first year of treatment. J Headache Pain 17:48

32. Grazzi L, Usai S (2015) Onabotulinum toxin A (Botox) for chronic migraine treatment: an Italian experience. Neurol Sci 36(Suppl 1):33-35

33. Kollewe K, Escher CM, Wulff DU, Fathi D, Paracka L, Mohammadi B, Karst M, Dressler D (2016) Long-term treatment of chronic migraine with OnabotulinumtoxinA: efficacy, quality of life and tolerability in a real-life setting. J Neural Transm (Vienna) 123:533-540

34. Allergan plc Botox ${ }^{\circledast}$ (onabotulinumtoxinA for injection). Summary of Product Characteristics, Allergan plc, Irvine, CA, USA, 2015. Botox (onabotulinumtoxinA for injection). Summary of Product Characteristics, Allergan plc, Irvine, CA, USA, 2015

35. Blumenfeld A, Silberstein SD, Dodick DW, Aurora SK, Turkel CC, Binder WJ (2010) Method of injection of onabotulinumtoxinA for chronic migraine: a safe, well-tolerated, and effective treatment paradigm based on the PREEMPT clinical program. Headache 50:1406-1418. doi:10.1111/j.1526-4610. 2010.01766.x

36. Martin BC, Pathak DS, Sharfman MI, Adelman JU, Taylor F, Kwong WJ, Jhingran P (2000) Validity and reliability of the migraine-specific quality of life questionnaire (MSQ version 2.1). Headache 40:204-215

37. Cole JC, Lin P, Rupnow MF (2007) Validation of the Migraine-Specific Quality of Life Questionnaire version 2.1 (MSQ v. 2.1) for patients undergoing prophylactic migraine treatment. Qual Life Res 16:1231-1237. doi:10.1007/ s11136-007-9217-1

38. Walters SJ, Brazier JE (2005) Comparison of the minimally important difference for two health state utility measures: EQ-5D and SF-6D. Qual Life Res 14:1523-1532

39. Meletiche DM, Lofland JH, Young WB (2001) Quality-of-life differences between patients with episodic and transformed migraine. Headache 41: $573-578$
40. Wang SJ, Wang PJ, Fuh JL, Peng KP, Ng K (2012) Comparisons of disability, quality of life, and resource use between chronic and episodic migraineurs: a clinic-based study in Taiwan. Cephalalgia. doi:10.1177/0333102412468668

41. Katsarava Z, Buse DC, Manack AN, Lipton RB (2012) Defining the differences between episodic migraine and chronic migraine. Curr Pain Headache Rep 16:86-92. doi:10.1007/s11916-011-0233-z

42. Garcia Villar J, Quintana-Domeque C (2009) Income and body mass index in Europe. Econ Hum Biol 7:73-83. doi:10.1016/j.ehb.2009.01.006

43. Fryar CD, Gu Q, Ogden CL (2012) Anthropometric reference data for children and adults: United States, 2007-2010. Vital Health Stat 111-48

44. Manack Adams A, Serrano D, Buse DC, Reed ML, Marske V, Fanning KM, Lipton RB (2015) The impact of chronic migraine: the Chronic Migraine Epidemiology and Outcomes (CaMEO) Study methods and baseline results. Cephalalgia 35:563-578. doi:10.1177/0333102414552532

45. Stewart WF, Wood GC, Manack A, Varon SF, Buse DC, Lipton RB (2010) Employment and work impact of chronic migraine and episodic migraine. J Occup Environ Med 52:8-14. doi:10.1097/JOM.0b013e3181c1dc56

46. Martelletti P, Katsarava Z, Lampl C, Magis D, Bendtsen L, Negro A, Russell MB, Mitsikostas DD, Jensen RH (2014) Refractory chronic migraine: a consensus statement on clinical definition from the European Headache Federation. J Headache Pain 15:47

\section{Submit your manuscript to a SpringerOpen ${ }^{\circ}$ journal and benefit from:}

- Convenient online submission

- Rigorous peer review

- Open access: articles freely available online

- High visibility within the field

- Retaining the copyright to your article

Submit your next manuscript at springeropen.com 